\title{
Indicador nacional de alfabetismo funcional-2001: explorando as diferenças entre mulheres e homens
}

Amélia Cristina Abreu Artes

Universidade de São Paulo

Correspondência:

Amélia Cristina Abreu Artes

Rua Sepetiba, 224

05052-000 - São Paulo - SP

e-mail: a.artes@uol.com.br

\section{Resumo}

Este trabalho se insere em um conjunto de estudos na área educacional que investigam as diferenças nos resultados que homens e mulheres apresentam em pesquisas educacionais. 0 Indicador Nacional de Alfabetismo Funcional é composto por um teste com 20 questões de dificuldade variada, que mensura como as pessoas utilizam-se da escrita e da leitura em seus espaços cotidianos, tendo sido desenvolvido pelo Instituto Paulo Montenegro (IBOPE) e Ação Educativa e aplicado a uma amostra estratificada da população brasileira, composta de 2.000 pessoas (15 a 64 anos). Os resultados indicam que as mulheres apresentam um resultado melhor em todas as questões do teste na comparação com os homens. Utilizando o conceito de gênero e afastando-se da dicotomia homem-mulher, trabalhou-se com três grupos ocupacionais: homens que trabalham; mulheres que trabalham fora e donas-de-casa. A análise inferencial realizada indica que as diferenças entre as proporções médias de acertos nos três grupos ocupacionais são significativas, uma vez controladas as cinco variáveis preditoras (escolaridade, idade, cor, Critério Brasil e gosto por leitura). Isso sugere que as diferenças encontradas entre os grupos independem dessas variáveis preditoras. $\mathrm{Na}$ análise questão a questão, observa-se que, para nove destas, as mulheres que trabalham apresentam um desempenho médio superior aos homens que trabalham ou donas-de-casa. 0 que mais surpreende é que em três questões as donas-de-casa apresentam um desempenho significativamente superior aos homens que trabalham.

\section{Palavras-chave}

Letramento - Alfabetismo - Sexo e gênero. 


\section{The National Index of Functional Literacy - 2001: examining the differences between men and women*}

Amélia Cristina Abreu Artes

Universidade de São Paulo

\section{Contact:}

Amélia Cristina Abreu Artes

Rua Sepetiba, 224

05052-000 - São Paulo - SP

e-mail:a.artes@uol.com.br

\footnotetext{
"This article results from the author's Master Dissertation, presented in December 2004 to the Faculty of Education of the University of São Paulo, and developed under the supervision of Professor Marilia Pinto de Carvalho.
}

\begin{abstract}
This work is part of a group of studies in the educational field that investigate the differences in the results obtained by men and women in educational researches. The National Index of Functional Literacy is composed from a test of 20 questions of varying difficulty that measure how people make use of reading and writing in their daily activities. It was developed by the Paulo Montenegro Institute (IBOPE) and Educative Action (Ação Educativa), and applied to a stratified sample of the Brazilian population comprised of 2000 people (from 15 to 64 years of age). The results indicate that women perform better in every question of the test. Making use of the concept of gender and moving away from the man-woman dichotomy, we have worked with three occupational groups: working men, working women, and housewives. The inferential analysis carried out indicates that the differences in the average rate of right answers between the three occupational groups are significant, after accounting for the five predictive variables (schooling, age, color, Criterion Brazil, and reading habit). This suggests that the differences encountered between the groups are not dependent on the predictive variables. In a question by question analysis, it was observed that in nine of the questions the average performance of working women was superior to both working men and housewives. More surprisingly, in three of the questions housewives achieved significantly better results than working men.
\end{abstract}

\section{Keywords}

Literacy - Sex and gender. 
0 material analisado neste artigo são os resultados do Indicador Nacional de Alfabetismo Funcional (INAF), formado por um questionário de caracterização dos respondentes e um teste com 20 questões. 0 INAF, uma iniciativa do Instituto Paulo Montenegro (IBOPE) em parceria com a ONG Ação Educativa, tem como finalidade divulgar periodicamente informações a respeito do letramento de jovens e adultos. Avaliam-se as habilidades em escrita e leitura (anos ímpares) e matemática (anos pares), procurando analisar, nos anos pares, a inserção da população na cultura letrada, isto é, avaliar suas habilidades de alfabetismo/letramento. A base de dados aqui analisada refere-se ao ano de 2001.

0 objetivo é trazer subsídios para a compreensão dos diferentes resultados obtidos por homens e mulheres em uma pesquisa amostral, entendendo essa diferença como um produto cultural construído socialmente, já que homens e mulheres ocupam espaços sociais diversificados.

Uma vez que os resultados preliminares divulgados pelos organizadores indicavam um melhor desempenho das mulheres no teste, pretendemos neste estudo responder às seguintes questões:

- Quando se analisa cada questão do teste de letramento separadamente, há diferenças nos resultados, isto é, há questões em que as mulheres se saem melhor do que os homens? - Há diferença nos resultados quando se separa o grupo de mulheres em trabalhadoras e donas-de-casa?

0 INAF se insere em uma tendência mundial de avaliação educacional, cujos estudos podem ser divididos em três blocos: censos demográficos; contextos escolares; e estudos amostrais.

Os censos demográficos apresentam dados macrorregionais que podem ser analisados em diferentes recortes. No Brasil, autores como Alceu Ferraro (2002) e Fúlvia Rosemberg (2001) trabalham esses dados analisando a situação educacional brasileira.
Os estudos em contexto escolar caracterizam-se por avaliações de sistema, uma tendência mundial nos últimos anos conhecida por avaliar estudantes em suas habilidades de letramento associadas à escolarização. No Brasil, o SAEB (Sistema de Avaliação da Educação Básica), aplicado pelo Ministério da Educação, tem como objetivo apresentar informações sobre a qualidade, a equidade e a eficiência de nosso Ensino Básico. Internacionalmente, o PISA (Programa Internacional de Avaliação de Estudantes), organizado pela OCDE (Organização para Cooperação e Desenvolvimento Econômico), pretende verificar, em seus paísesmembros, até que ponto alunos próximos do término da Educação obrigatória adquiriram conhecimentos e habilidades essenciais para a participação social.

0 INAF se insere na categoria de estudos por amostragem. Em alguns países, a preocupação em testar o nível de letramento da população é uma realidade há décadas (nos Estados Unidos, por exemplo, esses estudos datam dos anos 1970), tendo como preocupação não só verificar se as pessoas sabem ou não ler e escrever, mas o quanto elas se utilizam de suas habilidades de leitura e escrita para inserir-se socialmente, já que o problema do analfabetismo absoluto concentra-se hoje nos países mais pobres do mundo. No Brasil, são raros estudos por amostragem com esse perfil, o que apenas ressalta a importância dos dados obtidos pelo INAF.

\section{Letramento e gênero}

Para desenvolver a análise, utilizamos dois conceitos centrais: letramento e gênero. Podemos dizer que são conceitos recentes, pois datam de meados do século passado e que foram construídos de acordo com diferentes áreas do conhecimento.

Em um relevante trabalho, publicado em 2002, com o título Letramento: um tema em três gêneros, Magda Soares discute o surgimento dos conceitos, associado à percepção de novos fenômenos na sociedade: 
[...] na língua sempre aparecem palavras novas quando fenômenos novos ocorrem, quando uma nova idéia, um novo fato, um novo objeto surgem, são inventados, e então é necessário ter um nome para aquilo. (Soares, 2002a, p. 34)

A autora ressalta ainda que durante muito tempo utilizou-se o termo analfabetismo, um substantivo que indica negação, falta $(\mathrm{a}[\mathrm{n}]+$ alfabetismo=privação de alfabetismo). 0 mesmo acontece na língua inglesa, cujo termo illiteracy (ausência de letramento) está dicionarizado desde 1660, no Oxford English Dictionary (1979), ao passo que o termo afirmativo, literacy, só aparece registrado no século XIX (Soares, 2002a).

A palavra letramento foi dicionarizada no Brasil apenas em 2001, pelo Dicionário Houaiss, na rubrica de pedagogia, e definida como o "mesmo que alfabetização (processo), conjunto de práticas que denotam a capacidade de uso de diferentes tipos de material escrito" (Houaiss, 2001). Apesar dessa demora, o termo já era utilizado havia algum tempo em escritos na área da Educação (Kato, 1986; Tfouni,1988; Soares, 2002b).

Para Soares, o letramento se caracteriza como uma prática social multifacetada, isto é, pode desenvolver-se em vários espaços, inclusive no escolar, e das mais variadas maneiras: uma criança está fazendo o "uso social da leitura" ao brincar de ler um livro infantil; um adulto pouco escolarizado pode ser considerado letrado ao recitar partes da Bíblia em uma cerimônia religiosa. Sua definição de letramento, apresentada em 2002, passou a ser referência nos estudos que tratam do tema:

Letramento é, pois, o resultado da ação de ensinar ou de aprender a ler e escrever: o estado ou a condição que adquire um grupo social ou um indivíduo como conseqüência de ter-se apropriado da escrita. (Soares, 2002a, p. 18)

Neste artigo, ainda de acordo com Soares (2004), utilizamos alfabetismo em sua perspectiva sociológica, que compreende as práticas de leitura e escrita como produtos culturais, os quais sofrem influências diretas das diferentes características demográficas como escolaridade, profissão e sexo. Nesse sentido, é importante não só explorar os resultados obtidos em um teste de letramento, como também levantar hipóteses a respeito das motivações que as pessoas possuem para a leitura, o valor simbólico que o ler ocupa nos diferentes contextos sociais e seu lugar na hierarquia dos bens culturais.

Portanto, o letramento não será considerado neutro, destituído de poder, e será contextualizado como conjunto de práticas socialmente construídas - que envolvem a leitura e a escrita -, geradas por processos sociohistóricos amplos e também responsáveis por referendar ou questionar valores, tradições e formas de distribuição de poder em nossa estrutura social. Dentre essas relações de poder, neste estudo, terão destaque as relações de gênero.

$\mathrm{Na}$ área educacional, não há muitos estudos que analisam as diferenças nos resultados de meninas/mulheres e meninos/homens em testes escolares, o que torna inédita a análise aqui proposta em um estudo amostral.

0 conceito de gênero surgiu no âmbito dos estudos feministas em busca de um deslocamento da explicação da diferença e da desigualdade entre homens e mulheres do campo da natureza para uma visão sociológica, segundo a qual os lugares do masculino e do feminino na sociedade são produzidos por relações sociais e históricas.

Assim como o par letramento/ alfabetismo, o conceito de gênero é recente, ainda em construção, e apresenta diferentes enfoques. Joan Scott (1995) enfatiza a necessidade de atenção às linguagens e aos significados das diferenças percebidas entre os sexos na elaboração de todo sistema simbólico, que permeia as relações de poder na sociedade. No artigo Gênero, uma categoria útil de análise histórica, a autora afirma que

[...] o uso de 'gênero' enfatiza todo um sistema de relações que pode incluir o sexo, mas não é diretamente determinado pelo 
sexo, nem determina diretamente a sexualidade. (p. 7)

Essa separação entre gênero e sexo é central para a compreensão do próprio conceito de gênero, no qual os elementos sociais, políticos e culturais passam a ser determinantes da interpretação que se faz do que é ser homem ou ser mulher. Segundo a pesquisadora francesa Christine Delphy, gênero deve ser entendido como um produto social que constrói o sexo:

Se as relações de gênero não existissem, o que conhecemos como sexo seria destituído de significado e não seria percebido como importante. Poderia ser apenas uma diferença física entre outras. (Delphy apud Auad, 2004, p. 28)

Para os fins deste artigo, o gênero será entendido

[...] não apenas como um conceito que descreve as relações entre homens e mulheres, mas como uma categoria teórica referida a um conjunto de significados e símbolos construídos sobre a base da percepção da diferença sexual. (Carvalho, 1999a, p. 34)

Nesse sentido, o conceito de gênero poderá ser útil para explicar as diferenças percebidas estatisticamente por meio da variável sexo, ao permitir levantar hipóteses sobre os significados culturais envolvidos no processo de letramento para as mulheres.

Fica claro que gênero não é sinônimo de sexo: uma coisa são os sujeitos, homens e mulheres; outra são os diferentes significados e símbolos que masculino e feminino ocupam histórica e socialmente, implicando relações de poder e hierarquias nos diferentes níveis. Os respondentes do INAF são homens e mulheres e serão tomados segundo essas categorias, sem questionar, porém, o lugar masculino ou feminino que possam hipoteticamente ocupar, procedimento esse que não se ajustaria a uma pesquisa quantitativa desta envergadura.
Nas últimas décadas, a questão da apropriação diferenciada da leitura por homens e mulheres vem sendo abordada por diversas áreas de pesquisa. No caso dos meninos e das meninas, principalmente dentro do espaço escolar, há inúmeros autores que indicam essas discrepâncias (Corrêa, 2004; Gilbert; Gilbert, 1998), sempre na direção de que as meninas têm maior afinidade com as práticas de leitura e melhor desempenho nos testes que avaliam letramento. Por outro lado, não foram encontrados estudos de gênero que explorem a questão do letramento na vida adulta.

Elaine Millard (1998), em artigo publicado no periódico Gender and Education, afirma que meninos apropriam-se da prática de leitura a partir de suas identidades de gênero. Para ela, essas diferenças estão diretamente associadas a uma identidade feminina marcada pela passividade, próxima da postura exigida para um leitor mais assíduo.

Resultados semelhantes a esses foram descritos na década de 1990 por Luke (1993) e Gilbert e Gilbert (1998). Esses últimos trataram da questão dos testes de letramento realizados na Austrália, ressaltando os diferentes resultados encontrados entre meninos e meninas. Os autores levantam dúvidas a respeito da forma como esses testes foram elaborados, assim como dos conteúdos cobrados e valorizados, o que indicaria uma possível incompatibilidade entre a masculinidade valorizada por esses jovens e as áreas curriculares valorizadas pela escola. Nessa interpretação, quando a leitura é vista como um comportamento femi-nilizado, os meninos tenderiam a rejeitá-la (Gilbert; Gilbert, 1998).

Há poucas pesquisas no Brasil que exploram a apropriação da leitura a partir da variável sexo. Pesquisa qualitativa, realizada por Maria Celeste Arantes Corrêa (2004), na qual se procurou verificar a preferência de leitura em meninos e meninas em idade escolar, indica que, comparativamente aos meninos, as meninas lêem mais livros e de diferentes gêneros literários.

Se partimos da concepção de que a leitura é uma prática cultural e histórica ou, como 
afirma Roger Chartier (1996), que ela "possui o estatuto de uma prática criadora, inventiva e produtiva, influenciada pelo espírito de seus leitores" (p. 78), devemos considerar na análise das práticas de letramento, entre outras relações sociais, as relações de gênero.

\section{O Indicador Nacional de Alfabetismo Funcional - INAF}

0 INAF está inscrito no contexto de uma sociedade grafocêntrica, em que o domínio da escrita e da leitura se apresenta como determinante da inclusão e exclusão social. 0 objetivo desse levantamento é:

[...] criar um indicador nacional de alfabetismo funcional cujos resultados pudessem ser periodicamente divulgados à população em geral, servindo como referência para o debate sobre o que deveria ser um dos principais resultados da escolarização básica: a capacitação dos indivíduos para inserir-se na cultura letrada de maneira autônoma, flexível e criativa. (Ribeiro, 2003, p. 50)

Até o segundo semestre do ano de 2005, já foram realizados cinco levantamentos: o INAF 2001, que avaliou as habilidades de leitura e é objeto de análise deste trabalho; os INAF 2002 e 2004, que versam sobre conhecimentos de matemática; e os INAF 2003 e 2005, que voltaram a avaliar habilidades de leitura.

Grande parte do relato do INAF 2001 aqui apresentado está baseado no artigo de Vera Masagão Ribeiro (2001), assim como em Ribeiro, Vóvio e Moura (2003) e que descreve com precisão o caminho trilhado na construção do indicador.

Para fomentar o debate público sobre a temática e auxiliar na construção do indicador, a ONG Ação Educativa e o Instituto Paulo Montenegro organizaram um seminário, realizado em setembro de 2001. Esse seminário reuniu especialistas no tema, gestores de programas educacionais e profissionais de jornalismo que discutiram o interesse social e a relevância da criação de um indicador dessa natureza.

Para orientar a construção dos instrumentos de coleta de dados, foram elaboradas matrizes relativas às esferas de práticas de letramento.

Para cada esfera, foram arrolados os suportes de escrita, os gêneros textuais, as funções que caracterizam as práticas de leitura e escrita e as competências gerais e específicas relacionadas a essas diferentes práticas. Dessa análise, resultaram dois instrumentos: um questionário e um teste de leitura.

A definição operacional de letramento utilizada na pesquisa é a mesma apresentada por Magda Soares (2002a).

A pesquisa foi operacionalizada pelo IBOPE em setembro de 2001. Utilizou-se uma amostra nacional de 2.000 pessoas de 15 a 64 anos. A equipe técnica do IBOPE definiu essa amostra a partir de um amplo conjunto de informações de que o Instituto dispunha a respeito da população-alvo, considerando ainda a especificidade do estudo.

0 questionário é constituído de 68 perguntas que procuram abarcar as diferentes esferas de práticas de letramento. Investigam-se hábitos de leitura de livros, jornais e revistas nos mais diferentes espaços sociais, procurando identificar que usos da escrita, gêneros e suportes de textos estão presentes em cada um desses espaços. 0 acompanhamento de tarefas escolares de crianças e os hábitos de leitura são avaliados, assim como a importância que os textos escritos ocupam na vida dos respondentes, tanto para a obtenção e manutenção do emprego como nos espaços de lazer, recreação e participação política. Há itens que recolhem informações sobre a família de origem do entrevistado, cuja finalidade é compreender como as condições de letramento se reproduzem ou se alteram entre as gerações. Requisitam-se ainda informações sobre que estratégias as pessoas adotam, por exemplo, para localizar um número de telefone, ler uma placa ou sinalização, escrever ou ler uma carta pessoal. Avaliam-se também o acesso e o uso de computadores. 
0 teste que compõe o INAF é a parte do estudo que procura mensurar o nível de alfabetismo da população brasileira. 0 questionário é um complemento de suma importância, pois permite ampliar as informações que auxiliam na compreensão desse fenômeno bastante complexo. Podemos dizer que o questionário auxilia na construção do panorama do letramento, pois permite conhecer as práticas sociais de uso da leitura e da escrita. 0 teste, por sua vez, mensura os níveis de alfabetismo apresentados pela população, com referência aos níveis de habilidades nele demonstrados. Portanto, ao tratar do teste, uso o termo alfabetismo, como fizeram os organizadores do indicador.

Composto por 20 itens, o teste abarca um número reduzido de práticas sociais de letramento, entre as diversas existentes, que podem, assim, ser transformadas em questões. De acordo com os organizadores, foi necessário ajustar a duração do teste e a sua complexidade às condições de aplicação a uma amostra grande de indivíduos. Vale ressaltar que o teste é aplicado na residência dos indivíduos, nem sempre em condições ideais ou com a disponibilidade de tempo necessária.

Na construção do teste, os organizadores optaram pela verificação das habilidades mais recorrentes nas diferentes práticas de letramento, procurando aproximar ao máximo os textos e as tarefas àquelas mais freqüentes no cotidiano. As vinte tarefas propostas aos respondentes foram organizadas em uma revista de variedades, elaborada especialmente para a pesquisa. Apenas no item 7 requereu-se a consulta a outros materiais: um envelope para endereçamento e uma cópia de cédula de identidade.

Os 20 itens do teste foram apresentados aos entrevistados de quatro formas distintas:

- nos itens mais simples - de 1 a 6 -, o entrevistador lia a pergunta e as duas opções de resposta por questão, anotando as respostas dadas oralmente pelo entrevistado;

- no item 7, o entrevistado completava um formulário de endereçamento a partir de informações de uma cédula de identidade;
- nos itens de 8 a 10, as instruções eram lidas em voz alta pelo entrevistador, mas preenchidas pelo entrevistado;

- nos itens de 11 a 20, o próprio entrevistado lia as instruções e escrevia as respostas nos espaços correspondentes.

Em todos os itens, o entrevistador poderia auxiliar na localização do texto correspondente a cada questão dentro da revista.

\section{Homens e mulheres no INAF}

Conforme presente no relatório final do INAF 2001, há diferenças do desempenho das mulheres comparado ao dos homens. Carvalho e Moura (2003) ressaltam que a escolaridade e a situação atual de trabalho (doméstico para as donas-de-casa e externo para homens e mulheres) interferem nas práticas de leitura. No entanto, indicam desde logo que essas variáveis não explicam as diferenças encontradas nos resultados, pois a diferença persiste mesmo quando controladas, no modelo de análise estatística, a influência da escolaridade e situação de trabalho. As autoras ressaltam ainda que homens e mulheres possuem práticas de leitura divergentes: enquanto os homens preferem a leitura de jornais, as mulheres preferem ler revistas.

Partimos, portanto, da constatação já apresentada também no relatório INAF 2001 da diferença no desempenho de mulheres e homens, para procurar caracterizar essas diferenciações.

Para a análise dos resultados, os organizadores do Indicador atribuíram a cada um dos 2.000 sujeitos um escore, de acordo com o número de itens respondidos corretamente. A Tabela 1 indica o número total de acertos no teste por sexo.

A distribuição do total de acertos indica que as mulheres apresentam um desempenho melhor do que os homens. Considerando o patamar até 10 acertos (metade da prova), temos $48,9 \%$ do total de homens e $41 \%$ do total de mulheres. A partir de 16 acertos ( $4^{\circ}$ quartil), temos $24,4 \%$ de homens e $27,9 \%$ de mulheres. 
Tabela 1: total de acertos por sexo.

\begin{tabular}{|c|c|c|c|c|c|c|}
\hline \multirow{2}{*}{ Total de acertos } & \multicolumn{2}{|c|}{ Homem } & \multicolumn{2}{c|}{ Mulher } & \multicolumn{2}{c|}{ Total } \\
\cline { 2 - 7 } & freq & $\%$ & freq & $\%$ & freq & $\%$ \\
\hline 0 & 39 & 4,0 & 26 & 2,5 & 65 & 3,3 \\
\hline 1 & 33 & 3,4 & 27 & 2,6 & 60 & 3,0 \\
\hline 2 & 32 & 3,3 & 25 & 2,4 & 57 & 2,9 \\
\hline 3 & 43 & 4,4 & 28 & 2,7 & 71 & 3,6 \\
\hline 4 & 39 & 4,0 & 30 & 2,9 & 69 & 3,5 \\
\hline 5 & 64 & 6,6 & 36 & 3,5 & 100 & 5,0 \\
\hline 6 & 34 & 3,5 & 39 & 3,8 & 73 & 3,7 \\
\hline 7 & 52 & 5,3 & 54 & 5,3 & 106 & 5,3 \\
\hline 8 & 46 & 4,7 & 58 & 5,7 & 104 & 5,2 \\
\hline 9 & 53 & 5,4 & 51 & 5,0 & 104 & 5,2 \\
\hline 10 & 42 & 4,3 & 47 & 4,6 & 89 & 4,5 \\
\hline 11 & 54 & 5,5 & 56 & 5,5 & 110 & 5,5 \\
\hline 12 & 48 & 4,9 & 57 & 5,6 & 105 & 5,2 \\
\hline 13 & 48 & 4,9 & 69 & 6,7 & 117 & 5,8 \\
\hline 14 & 48 & 4,9 & 59 & 5,8 & 107 & 5,3 \\
\hline 15 & 62 & 6,4 & 76 & 7,4 & 138 & 6,9 \\
\hline 16 & 68 & 7,1 & 81 & 8,0 & 149 & 7,4 \\
\hline 17 & 63 & 6,5 & 72 & 7,0 & 135 & 6,7 \\
\hline 18 & 55 & 5,6 & 67 & 6,5 & 122 & 6,1 \\
\hline 19 & 35 & 3,6 & 46 & 4,5 & 81 & 4,0 \\
\hline 20 & 17 & 1,7 & 21 & 2,0 & 38 & 1,9 \\
\hline Total & 975 & 100 & 1025 & 100 & 2000 & 100 \\
\hline
\end{tabular}

Fonte: Ação Educativa, relatório interno, 2001.

Apesar de o desempenho no teste ser uma variável contínua, fez-se necessário o estabelecimento de faixas de desempenho, para a caracterização dos tipos de tarefas que cada grupo de pessoas é capaz de realizar. A construção dessas faixas de desempenho é um trabalho complexo, pois as habilidades manifestas no teste não são lineares, isto é, uma pessoa pode errar alguns itens considerados fáceis e acertar os mais difíceis, por diversos motivos, como a maior familiaridade com este ou aquele tema.

A definição das faixas de desempenho tem por base a análise dos itens que a maioria das pessoas com um determinado escore acerta. Os organizadores do INAF estabeleceram um patamar de 70\% de acertos para considerar que determinado grupo acerta um determinado item com muita freqüência e decidiram que seriam considerados analfabetos apenas os entrevistados que não acertaram nenhum ou até dois itens, lembrando que alguns itens solicitavam apenas o reconhecimento de partes escritas e não a decodificação de letras. A escolha desse termo pelos responsáveis pelo indicador visa chamar a atenção para uma parcela da população que, por não saber lidar minimamente com textos escritos, encontra-se em uma condição grave de exclusão social. Os três níveis de alfabetismo estão assim descritos no livro Letramento no Brasil:

$\S$ Nivel 1 de alfabetismo - corresponde à capacidade de localizar informações explícitas em textos muito curtos. Acertaram de 3 a 9 questões.

$\S$ Nível 2 de alfabetismo - corresponde àquelas pessoas que conseguem localizar informações em textos curtos e localizar informações em textos de extensão média. Acertaram de 10 a 15 questões.

$\S$ Nível 3 de alfabetismo - corresponde à capacidade de ler textos mais longos, podendo orientar-se por subtítulos, localizar mais de uma informação, de acordo com condições estabelecidas. Acertaram de 16 a 20 questões. (Ribeiro, 2003, p. 18-19)

A Tabela 1 e a Tabela 2 apresentam as faixas de desempenho no teste, por sexo.

Observamos que as mulheres apresentam um melhor desempenho no teste com uma concentração maior nos níveis 2 e 3 de alfabetismo.

\section{Trabalhadoras e donas-de-casa}

Já a partir das primeiras análises realizadas, observamos que o grupo das mulheres não poderia ser tratado como homogêneo. Parte do esforço recente e dos debates no âmbito dos estudos de gênero tem sido exatamente na direção de indicar a pluralidade de lugares sociais que diferentes grupos de homens e mulheres ocupam, buscando evitar abordagens bipolares que opõem homens contra mulheres (Carvalho, 1999a; Bruschini, 1992).

Tabela 2: Faixa de desempenho por sexo.

\begin{tabular}{|l|c|c|c|c|c|c|}
\hline \multirow{2}{*}{ Faixa de desempenho } & \multicolumn{4}{|c|}{ Sexo } & \multicolumn{2}{|c}{ Total } \\
\cline { 2 - 6 } & Masculino & Feminino & \multicolumn{2}{c}{} \\
\cline { 2 - 7 } & Freq. & $\%$ & Freq. & $\%$ & Freq. & $\%$ \\
\hline Até 2 acertos - analfabetos & 104 & 10,7 & 78 & 7,6 & 182 & 9,1 \\
\hline 3 a 9 acertos - nivel 1 de alfabetismo & 331 & 33,9 & 296 & 28,9 & 627 & 31,3 \\
\hline 10 a 15 acertos - nivel 2 de alfabetismo & 302 & 31,0 & 364 & 35,5 & 666 & 33,3 \\
\hline 16 a 20 acertos - nivel 3 de alfabetismo & 238 & 24,4 & 287 & 28,0 & 525 & 26,3 \\
\hline Total & 975 & 100 & 1025 & 100 & 2000 & 100 \\
\hline Fonte: Análise descritiva a partir da base de dados da INAF 2001.
\end{tabular}


Segundo raciocínio apresentado por Ribeiro (1999), no caso dos estudos de letramento, o grupo de mulheres poderia ser dividido em pelo menos duas unidades menores: as mulheres que trabalham fora e as donas-de-casa. Dessa forma, decidimos dividir o grupo de mulheres em donas-de-casa (27\% da amostra das mulheres) e aquelas que trabalham fora (50\% da amostra de mulheres) e comparar seus resultados com o grupo de homens que trabalham fora (77\% da amostra de homens). Ficaram de fora os desempregados, estudantes, aposentados e outros, de ambos os sexos, pela pluralidade de ocupações.

Após essa escolha, os resultados foram desagregados nos três grupos ocupacionais. Passamos então a analisar os resultados obtidos por grupo, tanto em relação ao total de acertos no teste como questão a questão. Percebemos que, no teste, as mulheres apresentavam um resultado superior ao dos homens de forma geral. Ao se separar as informações por grupo ocupacional, a diferença entre homens e mulheres que trabalham fora aumenta favoravelmente a estas. Por outro lado, quando se analisaram os resultados questão a questão, em grande parte delas, as mulheres que trabalham apresentaram um resultado significativamente superior ao dos dois outros grupos ocupacionais. Em alguns itens, as donas-de-casa apresentavam um resultado superior ao dos homens que trabalham.

Para compreender essas diferenças, optou-se pela construção de um modelo estatístico, realizada por um profissional da área ${ }^{1}$. 0 objetivo na construção do modelo era verificar se as diferenças observadas entre as proporções médias de acertos nos três grupos ocupacionais eram estatisticamente significativas, isto é, se as diferenças observadas não eram apenas um erro de amostragem. Não bastava comparar as médias dos resultados dos grupos, pois há uma série de variáveis, tais como escolaridade, idade, renda ou cor, que podem influenciar os resultados encontrados. No modelo estatístico, é possível comparar os diferentes grupos controlando a influência do conjunto de variáveis selecionadas e, assim, a diferença, quando observada, dever-se-á a características internas desses grupos.

A escolha do trabalho como critério de distinção no grupo de mulheres, há muito está presente nas discussões da sociologia do trabalho. Várias autoras, entre elas, Daniele Kergoat (1986), Helena Hirata e Daniele Kergoat (1994) e, no Brasil, Elizabeth Souza Lobo (1991) e Cristina Bruschini (1990; 1992; 1994; 1998), têm se preocupado com o lugar que a mulher trabalhadora ocupa na sociedade capitalista. Em linhas gerais, elas ressaltam que a diferença entre os sexos no trabalho é, muitas vezes, negada, para ocultar a exploração que as mulheres sofrem, por exemplo, ao se deixar de lado as ocupações precárias e desvalorizadas que se somam ao trabalho doméstico.

É importante ressaltar que a separação nos grupos ocupacionais: homens que trabalham, mulheres que trabalham e donas de casa, ocorreu a partir de um item do questionário que perguntava ao entrevistado "Qual destas é a sua situação atual de trabalho?" Sendo possível apenas a escolha de uma opção:

(1) Está trabalhando

(2) Está desempregado

(3) Está aposentado

(4) Está procurando emprego pela primeira vez

(5) Nunca trabalhou e não está procurando emprego

(6) É dona-de-casa

(7) Outra situação (vive de renda, recebe pensão, inválido etc.)

(8) Não sabe/ não respondeu

Pode-se argumentar da fragilidade em se construir a análise a partir da resposta a um único item do questionário, uma vez que algumas dessas escolhas poderiam ser sobrepostas: a pessoa vive de renda e é dona-de-casa ou está aposentada e é dona-de-casa etc. Nos dois exemplos citados, é possível pensar que as mulheres que declararam ser donas-de-casa, apesar da hipoté-

1. Rinaldo Artes, doutor em Estatística pela Universidade de São Paulo, trabaIhou voluntariamente no apoio à pesquisa ao construir o modelo estatístico. 
tica possibilidade de outra escolha, estão descrevendo o lugar social em que se colocam. E é para dar visibilidade a este lugar social das donas-decasa que se privilegiou este grupo ocupacional.

A Tabela 3 apresenta o desempenho no teste segundo o grupo ocupacional e demonstra, também, que as mulheres que trabalham têm um desempenho melhor do que os homens que trabalham. A análise inferencial apresentada a seguir confirma essa informação. No caso das donas-de-casa, o desempenho concentra-se nos níveis 1 ( 3 a 9 acertos) e 2 de alfabetismo (10 a 15 acertos).

Tabela 3: Desempenho por ocupação.

\begin{tabular}{|l|c|c|c|c|c|c|}
\cline { 2 - 7 } \multicolumn{1}{c|}{} & \multicolumn{2}{|l|}{$\begin{array}{l}\text { Homens que } \\
\text { trabalham }\end{array}$} & \multicolumn{2}{l|}{$\begin{array}{l}\text { Mulheres que } \\
\text { trabalham }\end{array}$} & \multicolumn{2}{l|}{$\begin{array}{l}\text { Mulheres } \\
\text { donas-de-casa }\end{array}$} \\
\cline { 2 - 7 } \multicolumn{1}{c|}{} & freq. & $\%$ & freq. & $\%$ & freq. & $\%$ \\
\hline Até 2 acertos - analfabeto & 85 & 11 & 27 & 5 & 35 & 13 \\
\hline $\begin{array}{l}\text { 3 a } 9 \text { acertos - nivel 1 de } \\
\text { alfabetismo }\end{array}$ & 262 & 35 & 142 & 28 & 98 & 36 \\
\hline $\begin{array}{l}10 \text { a 15 acertos - nivel 2 } \\
\text { de alfabetismo }\end{array}$ & 233 & 31 & 175 & 34 & 98 & 36 \\
\hline $\begin{array}{l}16 \text { a } 20 \text { acertos - nivel 3 } \\
\text { de alfabetismo }\end{array}$ & 169 & 23 & 166 & 33 & 42 & 15 \\
\hline Total & 749 & 100 & 510 & 100 & 274 & 100 \\
\hline
\end{tabular}

Fonte: Análise descritiva a partir da base de dados da INAF 2001.

A verificação da existência de diferença significativa quando os indivíduos são iguais em todas as variáveis selecionadas, exceto nos grupos ocupacionais, foi feita por meio do ajuste de um modelo estatístico. A escolha das variáveis explicativas baseou-se em pesquisas quantitativas já realizadas na área educacional (Ribeiro, 1999), as quais indicam que uma parcela do desempenho em um teste de proficiência pode ser explicada por esse conjunto de características da população, assim como nos resultados das análises já realizadas a partir do INAF e descritas no livro Letramento no Brasil.

\section{Variáveis demográficas}

As variáveis descritas a seguir tiveram seus possíveis efeitos controlados na construção do modelo estatístico.

\section{Idade}

Esse preditor de desempenho também está presente em outras pesquisas (IALS, 2000). Parte dos respondentes do INAF está em uma faixa etária em que a freqüência escolar ainda é uma realidade, principalmente entre os $15 \mathrm{e}$ 24 anos. É possível que o uso que esses jovens façam de leituras e materiais escritos no espaço escolar possa facilitar a participação no teste e no manuseio dos materiais utilizados.

As faixas etárias escolhidas foram: de 15 a 24 anos; de 25 a 34 anos; de 35 a 49 anos; e de 50 a 64 anos.

A Tabela 4 apresenta as diferenças por idade e ocupação.

A maior parte das donas-de-casa encontra-se na faixa de 25 a 34 anos, período em que muitas mulheres deixam de trabalhar no mercado formal para cuidar de seus filhos pequenos. Esse dado é complementado com a freqüência de mulheres na faixa de 35 a 49 anos que estão trabalhando. Vale ressaltar a proporção de moças entre 15 e 24 anos que se declaram donas-de-casa: próximo a $20 \%$.

Tabela 4: Ocupação e idade.

\begin{tabular}{|c|c|c|c|c|c|c|}
\cline { 2 - 7 } \multicolumn{1}{c|}{} & \multicolumn{2}{l|}{$\begin{array}{l}\text { Homens que } \\
\text { trabalham }\end{array}$} & \multicolumn{2}{l|}{$\begin{array}{l}\text { Mulheres que } \\
\text { trabalham }\end{array}$} & \multicolumn{2}{l|}{$\begin{array}{l}\text { Mulheres } \\
\text { donas-de-casa }\end{array}$} \\
\cline { 2 - 7 } & Freq. & $\%$ & Freq. & $\%$ & Freq. & $\%$ \\
\hline $15-24$ anos & 191 & 26 & 125 & 25 & 51 & 19 \\
\hline $25-34$ anos & 205 & 27 & 140 & 27 & 83 & 30 \\
\hline $35-49$ anos & 224 & 30 & 175 & 34 & 75 & 27 \\
\hline $50-64$ anos & 129 & 17 & 70 & 14 & 65 & 24 \\
\hline Total & 749 & 100 & 510 & 100 & 274 & 100 \\
\hline
\end{tabular}

Fonte: Análise descritiva a partir da base de dados da INAF 2001.

\section{Cor}

A questão da raça/cor foi apresentada ao entrevistado segundo as categorias utilizadas pelo IBGE (branca, preta/negra, parda, amarela e indígena). 0 acréscimo do termo negra, que costuma ser usado nos estudos sociológicos para indicar raça e não cor, provavelmente visava facilitar a compreensão ou escolha do entrevistado. As mesmas categorias são freqüentemente utilizadas nos trabalhos de coleta de dados (Telles, 2002) ${ }^{2}$.

Os dados foram organizados como: 1.

2. Devemos lembrar que, nos meios acadêmicos, discute-se sobre as dificuldades e incorreções em se trabalhar com as categorias do IBGE (Telles, 2003). 
brancos e 2. negros (incluindo os pretos e pardos). Desconsideramos nessas análises os grupos amarelo (70 entrevistados, correspondendo a 3,5\% da amostra) e indígena (68 entrevistados, correspondendo a 3,4\% da amostra), por sua baixa representatividade. A denominação negros, agregando os dados quantitativos referentes a pretos e pardos, também é utilizada por Hasenbalg (1979) e Silva (1980).

A Tabela 5 ilustra a distribuição dos grupos ocupacionais por raça. Observa-se uma maior predominância de mulheres brancas donas-decasa, contrapondo-se a uma maior freqüência de mulheres pretas no mercado de trabalho.

Tabela 5: Raça e ocupação.

\begin{tabular}{|c|c|c|c|c|c|c|}
\cline { 2 - 7 } \multicolumn{1}{c|}{} & \multicolumn{2}{|l|}{$\begin{array}{l}\text { Homem que } \\
\text { trabalha }\end{array}$} & \multicolumn{2}{l|}{$\begin{array}{l}\text { Mulher que } \\
\text { trabalha }\end{array}$} & \multicolumn{2}{c|}{ Dona-de-casa } \\
\cline { 2 - 7 } \multicolumn{1}{c|}{} & Freq. & $\%$ & Freq. & $\%$ & Freq. & $\%$ \\
\hline Brancos & 356 & 47.5 & 245 & 48 & 154 & 56.4 \\
\hline Pretos & 393 & 52.5 & 265 & 52 & 119 & 43.6 \\
\hline
\end{tabular}

Fonte: Análise descritiva a partir da base de dados da INAF 2001.

\section{Variáveis culturais e educacionais}

\section{Escolaridade}

Várias pesquisas indicam que a escolaridade é um forte preditor do desempenho em testes de proficiência (OECD-IALS, 2000; OECD-PISA 2000; Brasil-SAEB 2001). Segundo relatório do IALS, cada ano de escolaridade aumenta em 10 pontos o escore do desempenho naquele teste.

Para a organização dos dados de escolaridade, trabalhamos com quatro faixas: 1) até primário completo, que corresponde ao Ensino Fundamental 1;2) até ginásio completo, que corresponde ao Ensino Fundamental 11;3) até colégio completo, que corresponde ao Ensino Médio; e 4) até Superior Completo.

A Tabela 6 apresentam as faixas de escolaridade por grupo ocupacional.

A escolaridade das mulheres trabalhadoras é superior na comparação com os homens trabalhadores e com as donas-de-casa. Esse resultado pode ter influência no desempenho geral no teste. As donas-de-casa apresentam uma escolaridade mais baixa comparada com a dos homens que trabalham. Esses resultados coincidem com estudos na área de gênero, que indicam uma maior escolaridade das mulheres na comparação com os homens (Carvalho,1999b).

\section{Gosto pela leitura}

Segundo relatório do IALS, o escore de letramento no teste tem uma relação positiva com a prática de leitura cotidiana (OECD-IALS, 2000). Também Carvalho e Moura (2003) ressaltam, ao analisarem os resultados do INAF 2001, que as mulheres possuem uma relação mais positiva e freqüente com as práticas de leitura. Qual a influência dessa melhor relação com a leitura no desempenho final no teste?

Para verificar essa hipótese, foi acrescentada ao modelo estatístico uma pergunta (questão 17) do questionário de caracterização, por meio da qual se indagava ao entrevistado se ele "gosta ou não gosta de ler para se distrair ou passar o tempo". Caso o gosto pela leitura, controladas as demais variáveis, se mostrasse uma variável preditora mais poderosa que o sexo lou grupo ocupacional) dos respondentes, poderíamos afirmar que os melhores resultados no tes-

Tabela 6: Escolaridade e ocupação.

\begin{tabular}{|l|c|c|c|c|c|c|}
\cline { 2 - 7 } \multicolumn{1}{c|}{} & \multicolumn{2}{c|}{$\begin{array}{c}\text { Homens que } \\
\text { trabalham }\end{array}$} & \multicolumn{2}{c|}{$\begin{array}{c}\text { Mulheres que } \\
\text { trabalham }\end{array}$} & \multicolumn{2}{c|}{$\begin{array}{c}\text { Mulheres donas-de- } \\
\text { casa }\end{array}$} \\
\cline { 2 - 7 } \multicolumn{1}{c|}{} & Freq. & $\%$ & Freq. & $\%$ & Freq. & $\%$ \\
\hline Até primário completo & 377 & 51 & 196 & 39 & 155 & 57 \\
\hline Até ginásio completo & 189 & 25 & 139 & 27 & 81 & 29 \\
\hline Até colégio completo & 127 & 17 & 117 & 23 & 31 & 11 \\
\hline Até superior completo & 56 & 7 & 58 & 11 & 7 & 3 \\
\hline Total & 749 & 100 & 510 & 100 & 274 & 100 \\
\hline
\end{tabular}

Fonte: Análise descritiva a partir da base de dados da INAF 2001. 
Tabela 7: Gosto por leitura e ocupação.

\begin{tabular}{|l|c|c|c|c|c|c|}
\cline { 2 - 7 } \multicolumn{1}{c|}{} & \multicolumn{2}{c|}{$\begin{array}{l}\text { Homem que } \\
\text { trabalha }\end{array}$} & \multicolumn{2}{l|}{$\begin{array}{l}\text { Mulher que } \\
\text { trabalha }\end{array}$} & \multicolumn{2}{c|}{ Dona-de-casa } \\
\cline { 2 - 7 } \multicolumn{1}{c|}{} & Freq. & $\%$ & Freq. & $\%$ & Freq. & $\%$ \\
\hline Gosta & 440 & 60.8 & 388 & 78.5 & 180 & 69.2 \\
\hline Não gosta & 284 & 39.2 & 106 & 21.5 & 80 & 30.8 \\
\hline
\end{tabular}

Fonte: Análise descritiva a partir da base de dados da INAF 2001.

te não decorreriam do fato de ser homem ou mulher, trabalhar fora ou ser dona-de-casa, mas estariam associadas a diferentes formas de apropriação da leitura. No modelo estatístico apresentado a seguir, observamos que o gosto por leitura é uma variável preditora do resultado final. No entanto, assim como o conjunto das outras variáveis elencadas, não explica a diferença encontrada entre os grupos ocupacionais.

Para a análise, as respostas foram organizadas em dois grupos: 1) gosta (englobando tanto os que declararam gostar muito e gostar pouco); e 2) não gosta (Tabela 7).

As mulheres trabalhadoras são as que

Tabela 8: Critério Brasil e ocupação.

\begin{tabular}{|c|c|c|c|c|c|c|}
\cline { 2 - 7 } \multicolumn{1}{c|}{} & \multicolumn{2}{c|}{ Homem que trabalha } & \multicolumn{2}{c|}{ Mulher que trabalha } & \multicolumn{2}{c|}{ Dona-de-casa } \\
\cline { 2 - 7 } \multicolumn{1}{c|}{} & Freq. & $\%$ & Freq. & $\%$ & Freq. & $\%$ \\
\hline Classe A/B & 119 & 15.9 & 76 & 14.9 & 28 & 10.3 \\
\hline Classe C & 228 & 30.4 & 172 & 33.7 & 97 & 35.5 \\
\hline Classe D/E & 402 & 53.7 & 262 & 51.4 & 148 & 54.2 \\
\hline
\end{tabular}

Fonte: Análise descritiva a partir da base de dados da INAF 2001.

com maior freqüência declaram gostar de ler como passatempo, seguidas das donas-de-casa.

\section{Variável situação \\ socioeconômica}

\section{Critério de Classificação Econômica Brasil - Critério Brasil}

O Critério Brasil inclui informações a respeito da posse de itens materiais e o grau de instrução do chefe da família, o que permite a melhor representação das classes econômicas, independente de pequenas variações de renda.

As faixas utilizadas no modelo estatístico são: Classe A/B; Classe C; Classe D/E (Tabela 8).

Observa-se que não há diferença nas distribuições dos grupos.

$\mathrm{Na}$ construção do modelo estatístico, fezse necessário a inclusão das possíveis interações de primeira ordem entre os fatores (grupo, es- colaridade, idade, gosto por leitura, Critério Brasil e cor) no modelo principal. Dizemos que existe uma interação de primeira ordem entre dois fatores quando a diferença entre as médias de um dos fatores varia conforme o nível do segundo fator. Por exemplo: pode-se ter resultados semelhantes entre homens e mulheres considerando os analfabetos, mas resultados diferentes quando se consideram pessoas com escolaridade alta. Nesse caso, dizemos que existe interação entre sexo e escolaridade. Uma vez ajustado o modelo principal, os efeitos não significativos (adotando-se o nível de significância de 5\%) foram sendo removidos do modelo, gerando modelos reduzidos. Isso foi sendo feito até que não restassem efeitos de interação não significativos.

A construção do modelo permite concluir que, uma vez controlados os fatores, há diferença estatisticamente significativa entre os três grupos ocupacionais analisados $(\mathrm{P}=0.009)$.

0 próximo passo consistiu na comparação das médias dos três grupos entre si. lsso foi feito por meio do teste de comparações múltiplas de Turkey (ver Neter et al., 1990), o qual nos permitiu concluir que a mulher que trabalha tem um desempenho médio melhor do homem que trabalha $(\mathrm{P}<0,001)$ e da dona-de-casa $(\mathrm{P}<0,001)$. Por outro lado, não se encontrou diferença significativa no desempenho médio (proporção média de acertos) de homens que trabalham e dona-de-casa $(\mathrm{P}=0.342)$.

Outra informação relevante é que as interações que envolvem os grupos não foram significativas. Isso sugere que as diferenças encontradas entre os três grupos ocupacionais independem do grau de escolaridade, da idade, do gosto por leitura, da classe econômica e da cor do participante.

\section{Análise questão a questão}

0 interesse pela análise das questões do teste por grupo ocupacional deve-se à inexistência de outros estudos que os analisem conforme esse modelo, separando o teste em unidades menores, no caso, questão a questão. Se há diferenças no 
conjunto do teste, quando se analisa o total de acertos ou os níveis de alfabetismo, em que ponto específico, isso é, em que item da prova essa diferença pode ser encontrada? Segundo os próprios organizadores do INAF, o teste abarca um reduzido número de práticas sociais de letramento, entre as diversas existentes, e que podem ser transformadas em questões. Juntando a isso a idéia de que as práticas sociais de leitura são apropriadas diferentemente por mulheres e homens, cabe indagar em que questões específicas as diferenças são encontradas.

Uma análise interna das questões do teste exigiria um estudo lingüístico que explorasse a construção das questões e o conjunto de habilidades que cada uma delas mensura. Só esse aspecto já poderia transformar-se em um novo trabalho. Assim, o que pretendemos é uma exploração inicial do conjunto de questões do teste, procurando analisar aspectos gerais nos itens em que se observam diferenças entre os grupos ocupacionais.

Se no teste como um todo as mulheres que trabalham apresentam um resultado melhor do que os outros dois grupos, essa diferença se mantém para todas as questões? Há questões em que as donas-de-casa se saem melhor do que os homens que trabalham? Que características possuem essas questões? A Tabela 9 apresenta o índice de acertos por questão e ocupação. Por exemplo, acertaram a primeira

Tabela 9: Freqüência e porcentagem de acertos por questão e ocupação.

\begin{tabular}{|c|c|c|c|c|c|c|}
\hline \multirow{2}{*}{ QUESTÕES } & \multicolumn{2}{|c|}{ Mulher que trabalha } & \multicolumn{2}{c|}{ Mulher dona-de-casa } & \multicolumn{2}{c|}{ Homem que trabalha } \\
\cline { 2 - 7 } & Freq. & $\%$ & Freq. & $\%$ & Freq. & $\%$ \\
\hline 01 & 443 & 87 & 222 & 81 & 597 & 80 \\
\hline 02 & 394 & 77 & 195 & 71 & 542 & 72 \\
\hline 03 & 408 & 80 & 192 & 70 & 512 & 68 \\
\hline 04 & 454 & 89 & 221 & 81 & 619 & 83 \\
\hline 05 & 464 & 91 & 224 & 82 & 633 & 85 \\
\hline 06 & 418 & 82 & 193 & 71 & 532 & 71 \\
\hline 07 & 260 & 51 & 107 & 40 & 316 & 42 \\
\hline 08 & 263 & 52 & 105 & 38 & 305 & 41 \\
\hline 09 & 293 & 57 & 121 & 44 & 310 & 41 \\
\hline 10 & 397 & 78 & 185 & 68 & 488 & 65 \\
\hline 11 & 335 & 66 & 149 & 55 & 377 & 50 \\
\hline 12 & 250 & 49 & 79 & 29 & 272 & 36 \\
\hline 13 & 202 & 40 & 81 & 30 & 254 & 34 \\
\hline 14 & 223 & 44 & 63 & 23 & 244 & 33 \\
\hline 15 & 284 & 56 & 102 & 38 & 299 & 40 \\
\hline 16 & 141 & 27 & 40 & 15 & 147 & 20 \\
\hline 17 & 275 & 54 & 109 & 40 & 351 & 47 \\
\hline 18 & 273 & 54 & 99 & 36 & 330 & 44 \\
\hline 19 & 221 & 43 & 90 & 33 & 280 & 37 \\
\hline 20 & 110 & 22 & 35 & 13 & 123 & 16 \\
\hline Fonte: Análise descritiva a partir da base de dados da INAF 2001. & \\
\hline
\end{tabular}

questão 87\% das mulheres que trabalham, 81\% das donas-de-casa e $80 \%$ dos homens que trabalham e assim sucessivamente. No conjunto, as mulheres que trabalham apresentam um maior indice de acertos em todas as questões do que os homens que trabalham e as donas-de-casa.

Em uma primeira análise, algumas questões se sobressaem e merecem atenção. A questão 5, por exemplo, solicitava que o entrevistado, a partir da reprodução de um cartaz de vacinação para idosos, informasse "Qual o dia e mês em que se inicia a vacinação?" Foi a questão que obteve o maior índice de acertos em todos os grupos. Essa é uma pergunta cuja resposta é imediata e representa uma situação cotidiana: a localização de uma informação explícita em um anúncio. 0 mesmo se pode dizer da questão 4 , em que, perante o mesmo cartaz, solicitava-se que se dissesse "A partir de que idade as pessoas podem tomar a vacina gratuitamente?"

Já o índice de acertos na questão 7 , na qual o entrevistado deveria preencher um formulário, retirando as informações necessárias de uma carteira de identidade e de um envelope endereçado, cai vertiginosamente, ficando abaixo de 50\% de acertos em todos os grupos, exceção para as mulheres que trabalham, com índice de 51\%. A tarefa de preencher um formulário não parece ser uma situação estranha ao cotidiano das pessoas, porém o nível de dificuldade que uma atividade como essa possui, ao exigir o manuseio de diferentes materiais e o correto preenchimento das informações solicitadas, pode ter influenciado seu baixo índice de acertos.

As questões 16 e 20 são as que apresentaram piores índices de acertos para todos os grupos, abaixo dos 30\%. Na questão 16, após a leitura de um conto popular envolvendo um caboclo, um padre, um estudante e um bagageiro, no qual o caboclo mostra ser o mais esperto de todos, o entrevistado deve responder por escrito às indagações: "Quem tem mais estudo sempre se dá melhor na vida? A história confirma essa frase? Por quê?" Ângela Kleiman (2003), em artigo publicado na coletânea Letramento no Brasil, critica esse item do teste, que se contrapõe ao senso 
comum, no qual a educação é vista como possibilidade de ascensão social, uma vez que, no conto, a esperteza do caboclo, que possivelmente possui menos escolaridade, é o determinante para sua conquista. Essa dupla mensagem provavelmente dificultou o índice de acertos.

A questão 20 obteve o mais baixo índice de acertos, provavelmente por ser a última do teste e exigir que o entrevistado localize uma informação não explícita em uma notícia que trata dos direitos dos consumidores.

A Tabela 10 (nas páginas 575 e 576) apresenta as conclusões obtidas a partir da regressão logística realizada separadamente nas questões do teste. A coluna 2 indica em que questões há diferenças na chance de acertar uma questão estando em um grupo ocupacional. Essa informação é apresentada por meio dos valores de nível de significância, quando a diferença for estatisticamente significativa e tendo controlado a possível influência das outras variáveis escolhidas como, por exemplo, compara-se hipoteticamente uma mulher que trabalha e um homem que trabalha com igual escolaridade, cor, idade, gosto por leitura e Critério Brasil. A única diferença entre os dois seria o grupo ocupacional a que pertencem. Já as cinco últimas colunas indicam as questões em que há diferença significativa dependendo da variável analisada na referida questão.

$\mathrm{Na}$ análise de chance de acerto, observamos que em nove questões há diferença significativa na proporção média de acertos, controladas as demais variáveis, em todos os casos favorável às mulheres que trabalham em comparação aos homens que trabalham ou donas-de-casa (questões: 8, 9, 10, $11,12,14,15,16$ e 18). 0 mais importante, entretanto, é verificar que, a partir da questão 8, o respondente tinha de escrever a resposta no caderno de questões do INAF, tarefa acrescida, a partir da questão 11 , da leitura das instruções para cada questão. Como entender esse resultado? Até que ponto o melhor desempenho das mulheres que trabalham pode ser creditado a uma maior proficiência em cada questão ou, diferentemente, apenas a uma maior disposição e empatia em realizar o teste?
Quando se compara a proporção média de acertos das donas-de-casa à dos homens que trabalham, controladas as demais variáveis, temos que para três questões $(8,9,11)$ a diferença é significativa e favorável a elas. Vale analisar separadamente cada uma.

Na questão 8, solicita-se, a partir da apresentação do sumário da revista, a definição de sua utilidade: "para que serve esta parte da revista?" Segundo os organizadores da pesquisa, esse item:

Foi incluído no teste como um indicador da familiaridade do leitor com recursos para localizar textos que se deseja ler ou para conhecer o conteúdo de uma publicação sem folheá-la toda. Ainda que sejam meios alternativos para buscar textos de interesse, esse é um recurso que facilita a organização e denota a familiaridade do respondente com materiais escritos diversos. (INAF, 2001, p. 9)

Conforme já descrito anteriormente, as mulheres lêem revistas com mais freqüência que os homens, os quais, por sua vez, preferem a leitura de jornais (Carvalho; Moura, 2003). A importância do sumário em cada um desses gêneros literários é diferente: enquanto na revista ele serve para a localização de reportagens de interesse, nos jornais, quando existente, é pouco relevante e pouco consultado. Até que ponto esse resultado mais favorável às donas-de-casa deve-se ao material utilizado?

No item 9, solicitava-se ao respondente que, após a leitura de uma notícia a respeito de como limpar a caixa d'água, indicasse "todos os materiais de que você precisa para limpar a caixa d'água”. Segundo os organizadores da pesquisa:

A maior dificuldade do item pode ser atribuída ao fato de que solicitava-se a localização de cinco itens de informação (os materiais necessários para a limpeza da caixa). Como não é possível, após a primeira leitura, memorizar os cinco itens, o leitor, para responder a pergunta, é obrigado a voltar 
Tabela 10: Análise questão a questão do teste: competência, chance de acerto e descrição.

\begin{tabular}{|c|c|c|c|c|c|c|c|}
\hline \multirow{2}{*}{ Questão } & \multirow{2}{*}{$\begin{array}{l}\text { Competência } \\
\text { avaliada }\end{array}$} & \multirow{2}{*}{$\begin{array}{c}\text { Chance de acerto na } \\
\text { comparação entre grupos } \\
\text { ocupacionais }\end{array}$} & \multicolumn{5}{|c|}{$\begin{array}{c}\text { Descrição das variáveis - diferença significativa - melhor } \\
\text { resultado }\end{array}$} \\
\hline & & & $\begin{array}{c}\text { Maior } \\
\text { escolaridade }\end{array}$ & $\begin{array}{l}\text { Gosta de } \\
\text { ler }\end{array}$ & $\begin{array}{l}\text { Maior nível } \\
\text { CCEB }\end{array}$ & $\begin{array}{l}\text { Menor } \\
\text { idade }\end{array}$ & Raça branca \\
\hline 01 & $\begin{array}{l}\text { Localizar informações } \\
\text { especificas na capa } \\
\text { da revista. }\end{array}$ & & $P<0.001$ & $P<0.001$ & $P<0.001$ & & \\
\hline 02 & $\begin{array}{c}\text { Relacionar a } \\
\text { ilustração com o } \\
\text { título. }\end{array}$ & & $P<0.001$ & $P<0.001$ & $P<0.001$ & & \\
\hline 03 & $\begin{array}{l}\text { Decodificar palavras e } \\
\text { frases, associando } \\
\text { grafemas e fonemas. }\end{array}$ & & $P<0.001$ & $P<0.001$ & $\begin{array}{c}\mathrm{C} \text { em } \\
\text { relação } \mathrm{D} / \mathrm{E} \\
\mathrm{P}<0.001\end{array}$ & & \\
\hline 04 & $\begin{array}{l}\text { Localizar informação } \\
\text { específica no } \\
\text { anúncio. }\end{array}$ & & $P<0.001$ & $P<0.001$ & $\begin{array}{c}\mathrm{C} \text { em } \\
\text { relação } \mathrm{D} / \mathrm{E} \\
\mathrm{P}<0.001\end{array}$ & & \\
\hline 05 & $\begin{array}{l}\text { Localizar informação } \\
\text { específica no } \\
\text { anúncio. }\end{array}$ & & $P<0.001$ & $P<0.001$ & $P=0.049$ & $\begin{array}{l}\mathrm{P}=0.012 \\
\text { cai a } \\
\text { partir } \\
\text { dos } 35 \\
\text { anos }\end{array}$ & \\
\hline 06 & $\begin{array}{l}\text { Localizar informação } \\
\text { especifica na carta } \\
\text { (texto curto e } \\
\text { simples). }\end{array}$ & & $P<0.001$ & $P<0.001$ & $\begin{array}{c}A / B \\
P=0.028-; C \\
P<0.001 \text { em } \\
\text { relação } D / E\end{array}$ & & $P=0.052$ \\
\hline 07 & $\begin{array}{l}\text { Localizar informação } \\
\text { especifica em } \\
\text { documento e conta; } \\
\text { utilizar letras legíveis } \\
\text { para preenchimento; } \\
\text { posicionar } \\
\text { adequadamente a } \\
\text { escrita no suporte de } \\
\text { acordo com o tipo de } \\
\text { formulário. }\end{array}$ & & $P<0.001$ & $P<0.026$ & $\begin{array}{l}\mathrm{C} \text { em } \\
\text { relação D/E } \\
\mathrm{P}<0.001\end{array}$ & $P=0.001$ & $P=0.033$ \\
\hline 08 & $\begin{array}{l}\text { Identificar a função } \\
\text { do texto (sumário). }\end{array}$ & $\begin{array}{c}\text { Mulher que trabalha } \\
(\mathrm{P}<0,006) \text { e dona-de-casa } \\
(\mathrm{P}<0,030) \text { com nivel } \\
\text { colégio têm resultado } \\
\text { superior a homem que } \\
\text { trabalha com nivel } \\
\text { colégio. }\end{array}$ & $P<0.001$ & $P<0.001$ & $\begin{array}{c}A / B \\
P<0.001-; C \\
P<0.001 \text { em } \\
\text { relação } D / E\end{array}$ & & \\
\hline 09 & $\begin{array}{l}\text { Localizar informação } \\
\text { especifica em texto } \\
\text { prescrito (texto } \\
\text { simples com extensão } \\
\text { média). }\end{array}$ & $\begin{array}{c}\text { Mulher que trabalha } \\
(P<0,001) \text { e dona-de-casa } \\
(P<0.013) \text { têm resultado } \\
\text { superior a homem que } \\
\text { trabalha. }\end{array}$ & $P<0.001$ & $P<0.001$ & $\mathrm{P}=0.019$ & $P<0.001$ & \\
\hline 10 & $\begin{array}{c}\text { Estabelecer relação } \\
\text { entre duas ou mais } \\
\text { informações (antes e } \\
\text { depois). }\end{array}$ & $\begin{array}{l}\text { Mulher que trabalha tem } \\
\text { resultado superior a } \\
\text { homem que trabalha } \\
(\mathrm{P}=0.002) .\end{array}$ & $P<0.001$ & $P<0.001$ & $P<0.001$ & $P<0.001$ & $P=0.087$ \\
\hline 11 & $\begin{array}{l}\text { Localizar informação } \\
\text { especifica em notícia } \\
\text { (texto com extensão } \\
\text { média). }\end{array}$ & $\begin{array}{c}\text { Mulher que trabalha } \\
(\mathrm{P}<0.006) \text { e dona-de-casa } \\
(\mathrm{P}<0.020) \text { têm resultado } \\
\text { superior a homem que } \\
\text { trabalha. }\end{array}$ & $P<0.001$ & $P<0.001$ & $\begin{array}{c}\mathrm{C} \text { em } \\
\text { relação } \mathrm{D} / \mathrm{E} \\
\mathrm{P}=0.001\end{array}$ & $P=0.033$ & \\
\hline 12 & $\begin{array}{l}\text { Estabelecer relação } \\
\text { entre fato e opinião } \\
\text { em notícia (texto } \\
\text { com extensão média). }\end{array}$ & $\begin{array}{l}\text { Mulher que trabalha tem } \\
\text { resultado superior a dona- } \\
\text { de-casa }(P=0.002) \text { e a } \\
\text { homem que trabalha } \\
(P=0,013) \text {. }\end{array}$ & $P<0.001$ & $P<0.001$ & $P=0.061$ & $P=0.048$ & \\
\hline 13 & $\begin{array}{l}\text { Localizar informação } \\
\text { especifica, utilizando } \\
\text { títulos, subtítulos e } \\
\text { outros elementos } \\
\text { para localizar a parte } \\
\text { do texto que } \\
\text { interessa. }\end{array}$ & & $P<0.001$ & $P=0.096$ & $P<0.001$ & & \\
\hline
\end{tabular}




\begin{tabular}{|c|c|c|c|c|c|c|c|}
\hline 14 & $\begin{array}{c}\text { Localizar informação } \\
\text { específica, utilizando } \\
\text { títulos, subtítulos e } \\
\text { outros elementos } \\
\text { para localizar a parte } \\
\text { do texto que } \\
\text { interessa; comparar } \\
\text { duas ou mais } \\
\text { informações; inferir } \\
\text { informação implícita. }\end{array}$ & $\begin{array}{l}\text { Homem que trabalha } \\
(\mathrm{P}=0.042) \text { e mulher que } \\
\text { trabalha }(\mathrm{P}<0.001) \text { têm } \\
\text { resultado superior a dona- } \\
\text { de-casa; mulher que } \\
\text { trabalha }(\mathrm{P}=0.031) \text { tem } \\
\text { resultado superior a } \\
\text { homem que trabalha. }\end{array}$ & $P<0.001$ & $\mathrm{P}=0.002$ & $P<0.001$ & & \\
\hline 15 & $\begin{array}{l}\text { Inferir informação } \\
\text { implícita em } \\
\text { narrativa (texto com } \\
\text { extensão média). }\end{array}$ & $\begin{array}{l}\text { Mulher que trabalha tem } \\
\text { resultado superior a dona- } \\
\text { de-casa }(\mathrm{P}=0.013) \mathrm{e} \\
\text { homem que trabalha } \\
(\mathrm{P}=0.001) .\end{array}$ & $P<0.001$ & $P<0.001$ & $P=0.002$ & & \\
\hline 16 & $\begin{array}{c}\text { Relacionar } \\
\text { informação textual } \\
\text { com conhecimentos } \\
\text { prévios em narrativa } \\
\text { (texto com extensão } \\
\text { média); identificar o } \\
\text { tema central da } \\
\text { narrativa. } \\
\end{array}$ & $\begin{array}{l}\text { Mulher que trabalha tem } \\
\text { resultado superior a dona- } \\
\text { de-casa ( } P=0.095) \text {. Nivel } \\
\text { de significância que dá } \\
\text { margem a dúvida. }\end{array}$ & $P<0.001$ & $P=0.001$ & $P<0.001$ & $P=0.042$ & \\
\hline 17 & $\begin{array}{l}\text { Localizar informação } \\
\text { específica em tabela } \\
\text { de dupla entrada, } \\
\text { utilizando elementos } \\
\text { organizadores para } \\
\text { localizar a } \\
\text { informação que } \\
\text { interessa; comparar } \\
\text { informação entre } \\
\text { duas tabelas. }\end{array}$ & & $P<0.001$ & $P<0.001$ & $\mathrm{P}=0.021$ & $\mathrm{P}=0.001$ & $P=0.047$ \\
\hline 18 & $\begin{array}{l}\text { Localizar informação } \\
\text { específica em } \\
\text { reportagem, } \\
\text { utilizando elementos } \\
\text { organizadores para } \\
\text { localizar a parte do } \\
\text { texto que interessa; } \\
\text { estabelecer relação } \\
\text { entre texto e } \\
\text { imagem. } \\
\end{array}$ & $\begin{array}{c}\text { Homem que trabalha } \\
(\mathrm{P}<0.001) \text { e mulher que } \\
\text { trabalha }(\mathrm{P}=0.004) \text { com } \\
\text { nivel superior têm } \\
\text { resultado superior a dona- } \\
\text { de-casa. }\end{array}$ & & $P<0.001$ & $P<0.001$ & $P<0.001$ & \\
\hline 19 & $\begin{array}{l}\text { Localizar informações } \\
\text { específicas em texto } \\
\text { prescritivo, utilizando } \\
\text { elementos } \\
\text { organizadores para } \\
\text { localizar a } \\
\text { informação que } \\
\text { interessa. }\end{array}$ & & $P<0.001$ & $P<0.001$ & & $P<0.001$ & \\
\hline 20 & $\begin{array}{l}\text { Localizar informação } \\
\text { específica utilizando } \\
\text { títulos, subtítulos e } \\
\text { outros elementos } \\
\text { para localizar a parte } \\
\text { do texto que } \\
\text { interessa na } \\
\text { reportagem; } \\
\text { estabelecer relação } \\
\text { entre partes do texto } \\
\text { e entre duas ou mais } \\
\text { informações. }\end{array}$ & & $P<0.001$ & $P=0.002$ & $P=0.001$ & & \\
\hline
\end{tabular}

Fonte: Ação Educativa, relatório interno, 2001. 
ao texto e conferir se de fato citou todos os materiais necessários (INAF, 2001, p. 8).

Não há como analisar a influência do conteúdo da questão no resultado alcançado, porém se pode afirmar que a limpeza e mesmo a caixa d'água estão mais presentes no universo doméstico, de maior preocupação de donas-decasa, do que no universo masculino. Por outro lado, qual a influência da necessária precisão de itens a serem citados para o correto preenchimento da questão?

Por fim, na questão 11, pergunta-se, a partir de uma notícia sobre um deslizamento, "Quantas pessoas morreram por causa do deslizamento?" Era necessária uma pequena inferência, já que a notícia trazia o nome das vítimas. Nessa questão em especial, foi difícil levantar hipóteses que justifiquem o resultado diferenciado, sendo necessários outros elementos para sua compreensão.

As conclusões advindas da análise das cinco colunas que descrevem o resultado por questão e variável reforçam o já descrito anteriormente. A escolaridade e o gosto por leitura são determinantes no resultado alcançado em todas as questões do teste: quanto maior a escolaridade, melhor o desempenho; e gostar de ler auxilia na realização do teste. A variável Critério Brasil também é determinante em dezenove questões, com diferença favorável às classes mais altas. Entretanto, para algumas questões, o número de respondentes por classe é insuficiente para que se diga que a diferença é estatisticamente significativa. Nesse caso, são apresentadas apenas as comparações estatisticamente significativas. A variável da idade passa a ser determinante, à medida que as questões vão tendo um maior grau de dificuldade. A relação é: quanto menor a idade, lembrando que o teste tem como faixa etária inicial os 15 anos, maior o índice de acertos. Já a variável raça indica diferença apenas nas questões 6, 7, 10 e 17, favorável aos brancos. Uma análise específica seria necessária para a compreensão desses resultados.
Na verdade, para a compreensão de todas as diferenças anotadas acima, faz-se necessária, como já indicado, uma análise lingüística de cada questão, para além das competências avaliadas: quais as habilidades medidas em cada questão? 0 quanto o conteúdo de cada questão está mais associado ao universo masculino ou feminino? Enfim, uma série de perguntas que poderiam ser construídas e que necessitariam de pesquisas específicas para sua resolução.

\section{Considerações finais: o enfoque de gênero em uma pesquisa de letramento}

Antes de mais nada, cabe destacar a relevância de uma pesquisa como o INAF para a mensuração dos níveis de alfabetismo da população brasileira, o que possibilita a construção de um quadro que retrata a forma como a leitura é apropriada e utilizada pela população deste país. É importante também ressaltar que as conclusões apresentadas só foram possíveis pela realização de uma análise estatística mais aprofundada dos dados, realizada por profissional capacitado na área. Parece-nos essencial que a área da Educação realize parcerias que permitam a análise de dados para além da comparação de médias ou apresentações descritivas das informações.

Em segundo lugar, por meio dos resultados diferenciados para mulheres e homens, buscamos destacar a importância de se considerar a perspectiva de gênero, como ferramenta na compreensão das diferentes práticas culturais, mais especificamente, na questão do letramento. 0 resultado inicial encontrado já indicava que há diferença entre os desempenhos de homens e mulheres no INAF quando se consideram as vinte questões do teste, com vantagem para as mulheres. Essa diferença, porém, não é propriamente uma novidade e está descrita na literatura tanto na análise do Indicador, como em outras pesquisas educacionais (Millard, 1998; INAF 2001; Gilbert; Gilbert, 1998; Corrêa, 2004). 0 que esse estu- 
do permitiu trazer à tona foi, em primeiro lugar, a inexistência de uma homogeneidade no grupo mulheres, rompendo a dicotomia mulherhomem tão freqüente nos estudos de gênero e em especial nos de caráter quantitativo, e colocando o trabalho como elemento diferenciador. Dessa forma, foi dado um passo para além do sexo do respondente ao se valorizar também o lugar social ocupado pelas mulheres, separadas nos grupos de trabalhadoras e donas-de-casa.

Após essa desagregação, o resultado até certo ponto ficou dentro do esperado: as mulheres que trabalham fora alcançaram um índice de acertos maior comparados aos homens que trabalham e às donas-de-casa, mas chama a atenção a semelhança nos resultados entre homens que trabalham e donas-de-casa. A carência de bibliografia que apresente informações a respeito das donas-de-casa e a ausência desse grupo de forma desagregada, nas estatísticas produzidas pelos principais institutos de pesquisa, nos fornecem poucos elementos para analisar essa semeIhança. Nossa insistência em destacar o grupo de donas-de-casa e seu desempenho decorre, entre outros motivos, dessa mesma carência, num esforço por começar a preencher essa lacuna.

Além da análise do desempenho total no teste, pretendeu-se também explorar a fundo o desempenho por questão. Os resultados encontrados indicam que em nove das vinte questões os índices médios de acertos das mulheres que trabalham fora são superiores a um ou aos dois outros grupos. Não há diferenças nas questões iniciais, consideradas hipoteticamente mais simples, assim como nas últimas questões, consideradas as de mais difícil resolução.

Mesmo não realizando uma análise aprofundada dessas questões em seu aspecto de construção lingüística, podemos levantar hipóteses sobre a influência que o conteúdo solicitado em cada questão pode ter no resultado alcançado pelos diferentes grupos. 0 que tem como conseqüência fundamental a preocupação em considerar se há elementos que possam estar mais próximos de conhecimentos prévios ou de interesses específicos de homens ou mulheres, que deveria estar presen- te tanto na elaboração das questões de um teste como na análise de seus resultados. Se o universo tratado em uma determinada questão for mais familiar a qualquer um dos sexos, isso implicaria, hipoteticamente, uma pequena vantagem para um dos lados na resolução da questão.

0 objetivo da construção de um modelo estatístico era o de garantir uma maior segurança nas conclusões obtidas e, dessa forma, verificar a influência de um conjunto de preditores, já discutidos na bibliografia sobre a temática, os quais poderiam explicar os resultados encontrados. A literatura informa que a escolaridade é o preditor principal no resultado alcançado em um teste de letramento, e relata também a influência da idade, renda ou classe. Acrescentamos a essa listagem a cor e o gosto pela leitura como variáveis explicativas.

0 resultado é, poderíamos dizer, desafiador: controladas as influências desse conjunto de variáveis, observamos que a diferença favorável às mulheres que trabalham fora permanece na comparação com os homens que trabalham e as donas-de-casa. Há algo além da escolaridade, idade, renda, cor ou gosto pela leitura que influencia o desempenho de homens e mulheres no Indicador. Se as análises estatísticas nos permitem chegar a tal conclusão, pouco nos auxiliam na explicação desses resultados, tarefa que cabe às Ciências Sociais. A que se devem, então, as diferenças encontradas entre as mulheres que trabalham e os outros dois grupos?

Sabemos, a princípio, que é fundamental o apoio em uma análise de gênero. Homens e mulheres apropriam-se diferentemente da leitura como práticas sociais e culturais que têm, entre outros, significados ligados ao gênero. Essa apropriação diferenciada - que se inicia normalmente no espaço escolar, mas não se limita a ele, pois está presente também nas atividades comunitárias, sociais, religiosas etc. - produz as diferenças observadas. Estudos qualitativos sobre as práticas de leitura e sobre os processos de letramento, que considerem com profundidade o gênero como categoria de análise, talvez possam abrir caminhos para a explicação que aqui permanece como indagação. 


\section{Referências bibliográficas}

AUAD, D. Relações de gênero nas práticas escolares: da escola mista ao ideal da educação. 2004. Tese (Doutorado)- Faculdade de Educação da Universidade de São Paulo. São Paulo, 2004.

BRASIL. Ministério da Educação e do Desporto. Instituto Nacional de Estudos e Pesquisas Educacionais. SAEB, 2001. Novas perspectivas. Brasília: INEP, 2001.

BRUSCHINI, C. Trabalho feminino no Brasil: novas conquistas ou persistência da discriminação? Meeting of the Latin American Studies Association. Chicago, 1998 (mimeo).

0 trabalho da mulher brasileira nas décadas recentes. Estudos Feministas, número especial, p. 179-199, 1994.

. 0 uso das abordagens quantitativas em pesquisas sobre relações de gênero. In: COSTA, A. de 0.; BRUSCHINI, C. Uma questão de gênero. São Paulo: Fundação Carlos Chagas, 1992.

Mulher, casa e família: cotidiano nas camadas médias paulistas. São Paulo: Fundação Carlos Chagas, 1990.

CARVALHO, M. P. de. Sucesso e fracasso escolar: uma questão de gênero. Educação e Pesquisa, São Paulo, v. 29, n. 1, jan./ jun. 2003.

Gênero e política educacional em tempos de incerteza. In:

No coração da sala de aula: gênero e trabalho docente nas séries iniciais. São Paulo: Xamã; Fapesp, 1999a.

Um olhar de gênero sobre as políticas educacionais. In: FARIA, N. (Org.). Gênero e educação. São Paulo: SOF, 1999b.

CARVALHO, M. P. de; MOURA, M. Homens, mulheres e letramento: algumas questões. In: RIBEIRO, V. M. (Org.). Letramento no Brasil. São Paulo: Global, 2003, p. 177-194.

CHARTIER, R. Práticas de leitura. São Paulo: Estação Liberdade, 1996.

CORRÊA, M. C. A. Preferências de leitura de meninos e meninas na escola implicam o papel da mulher professora e leitora? 2004. Dissertação (Mestrado)- Faculdade de Educação da Universidade de São Paulo, 2004.

FERRARO, A. R. Analfabetismo e níveis de letramento no Brasil: 0 que dizem os censos. Educação \& Sociedade, v. 23, n. 81, dez. 2002.

GILBERT, R.; GILBERT, P. Boys and books: masculinity goes to school. London; New York: Routledge, 1998.

GUIMARÃES, A. S. A. Raça e os estudos de relações raciais no Brasil. Novos Estudos, CEBRAP, n. 54, julho 1999.

HASENBALG, C. A. Discriminação e desigualdades raciais no Brasil. Rio de Janeiro: Graal, 1979.

HIRATA, H.; KERGOAT, D. A classe operária tem dois sexos. Estudos Feministas, v. 2, n. 3, p. 93-100, 1994.

HOUAISS, A. (Dir.). Dicionário Houaiss da língua portuguesa. São Paulo: Objetiva, 2001.

INDICADOR Nacional de Alfabetismo Funcional. INAF 2001: Relatório disponibilizado para a imprensa. 2001 (mimeo).

INAF 2001: Relatório disponibilizado para a imprensa. 2003 (mimeo).

KERGOAT, D. Relações sociais de sexo e divisão sexual do trabalho. In: LOPES, M. J. (Org.). Gênero e saúde. Porto Alegre: Artes Médicas, 1996.

KATO, M. No mundo da escrita. São Paulo: Ática, 1986.

KLEIMAN, Â. B. Avaliando a compreensão: letramento e discursividade nos teste de leitura. In: RIBEIRO, V. M. (Org.). Letramento no Brasil. São Paulo: Global, 2003, p. 209-228. 
LOBO, E. S. A classe operária tem dois sexos: trabalho, dominação e resistência. São Paulo: Brasiliense, 1991.

LUKE, A. On reading and sexual division of literacy. The School Field, v. 4, n. 3/4, Ljblana, 1993.

MILLARD, E. Gender identity and the construction of the developing reader. Gender and Education, v. 9, n. 1, p. 31-48, 1998.

NETER, J; WASSERMAN, W.; KUTRER, M. N. Applied linear statistical models, Mexico: McGraw Hill, 1990.

OECD, PISA. Relatório Nacional, 2000.

International Adult Literacy Survey: Final report. Paris: OECD, 2000.

Literacy, economy and society: results of the first international adult literacy survey. Paris: OECD, 1995.

PIZA, E.; ROSEMBERG, F. Cor nos censos brasileiros. In: CARONE, I.; BENTO, M. A. S. (Orgs.). Psicologia social do racismo: estudos sobre a branquitude e branqueamento no Brasil. Petrópolis: Vozes, 2002, p. 91-120.

RIBEIRO, V. M. Questões em torno da construção de indicadores de analfabetismo funcional e letramento. Educação e Pesquisa, São Paulo, v. 27, n. 2, p. 283-300, jul./dez. 2001.

Alfabetismo e atitude: pesquisas com jovens e adultos. Campinas: Papirus, 1999.

RIBEIRO, V. M.; VÓVIO, C. L.; MOURA, M. P. Letramento no Brasil: alguns resultados do indicador nacional de alfabetismo funcional. Educação e Sociedade, n. 81, v. 23, p. 49-70, dez. 2002.

ROSEMBERG, F. Educação formal, mulher e relações sociais de sexo/gênero: um balanço preliminar. São Paulo, 2001 (mimeo).

SILVA, N. do V. 0 preço da cor: diferenciais raciais na distribuição de renda no Brasil. Pesquisa e Planejamento Econômico. Rio de Janeiro, v. 10, n. 1, p. 21-44, 1980.

SCOTT, J. W. Gênero: uma categoria útil de análise histórica. Educação \& Realidade, Porto Alegre, n. 20, v. 2, p. 71-100, jul./dez. 1995.

SOARES, M. Letramento: um tema em três gêneros. Belo Horizonte: Autêntica, 2002a.

. Apresentação Dossiê letramento. Educação e Sociedade, n. 81, v. 23, p. 15-19, dez. 2002b.

. Alfabetização e letramento. São Paulo, Contexto, 2004.

TELLES, E. Racismo à brasileira: uma nova perspectiva sociológica. Rio de Janeiro: Relume Dumará; Fundação Ford, 2002.

TFOUNI, L. V. Adultos não alfabetizados: 0 avesso do avesso. São Paulo: Pontes Editores, 1988.

Recebido em 12.09.06

Aprovado em 13.08.07

Amélia Cristina Abreu Artes, doutoranda em Sociologia da Educação na Faculdade de Educação da Universidade de São Paulo, é docente da Universidade Bandeirante de São Paulo. 